\title{
Green synthesis and characterization of Ag nanoparticles from Mangifera indica leaves for dental restoration and antibacterial applications
}

\author{
Dola Sundeep $^{1}$ (D) T. Vijaya Kumar ${ }^{3}$ P. S. Subba Rao ${ }^{1}$ R. V. S. S. N. Ravikumar ${ }^{2}$. \\ A. Gopala Krishna ${ }^{1}$
}

Received: 29 November 2016/Accepted: 26 April 2017/Published online: 3 May 2017

(c) The Author(s) 2017. This article is an open access publication

\begin{abstract}
Green synthesis has gained a wide recognition as clean synthesis technique in the recent years. In the present investigation, silver nanoparticles were prepared by a novel green synthesis technique using Mangifera indica (Mango leaves) and found to be successfully used in dental applications. The prepared samples were spectroscopically characterized by XRD, PSA, SEM with EDS, and UV-Vis spectroscopy. The crystalline size and lattice strain were analyzed from the XRD data which were counter-verified by $\mathrm{W}-\mathrm{H}$ plots and particle size analyzer. The XRD peaks revealed that average crystalline size of the as-synthesized $\mathrm{Ag}$ nanoparticles was of $32.4 \mathrm{~nm}$ with face-centered cubic structure. This was counter-verified by particle size analyzer and Williamson-Hall plots and found to be 31.7 and $33.21 \mathrm{~nm}$ in the former and latter, and the crystalline size of Ag NPs could be concluded as $32 \pm 2 \mathrm{~nm}$. The morphological structure of the prepared sample was studied through SEM images and the chemical composition was analyzed by the EDS data. The band energy was calculated as $393 \mathrm{~nm}$ from UV-Vis, which confirmed the synthesized
\end{abstract}

Dola Sundeep

sundeepdola@gmail.com; dolasundeep@gmail.com

A. Gopala Krishna

dr.a.gopalakrishna@gmail.com

1 School of Nanotechnology, Center for Nano Science and Technology, Institute of Science and Technology (IST), Jawaharlal Nehru Technological University, Kakinada, Andhra Pradesh 533 003, India

2 Department of Physics, University College of Sciences, Acharya Nagarjuna University, Guntur, Andhra Pradesh, India

3 Department of Mechanical Engineering, K L University, Green Fields, Vaddeswaram, Guntur, Andhra Pradesh 522 520, India sample as Ag nanoparticles. To improve the mechanical bonding and hardness of the dentally used glass ionomer cement (GIC), the synthesized silver nanoparticles were incorporated into GIC in $2 \%$ weight ratio. The morphology of the prepared specimens was studied using optical microscope images. Vickers microhardness and Monsanto hardness tests were performed on GIC, GIC reinforced with microsilver particles and GIC reinforced with nanosilver particles and the latter derived a promising results. The results of the Monsanto tests confirmed the increase in hardness of the GIC reinforced with AgNps as $14.2 \mathrm{~kg} / \mathrm{cm}^{2}$ compared to conventional GIC and GIC reinforced with silver microparticle as 11.7 and $9.5 \mathrm{~kg} /$ $\mathrm{cm}^{2}$. Similarly the Vickers hardness results exhibited the enhanced hardness of GIC-reinforced AgNps as $82 \mathrm{VHN}$ compared to GIC as 54 and GIC-reinforced silver microparticles as $61 \mathrm{VHN}$. The antibacterial activity of AgNPs was tested by a well-diffusion method on Escherichia coli and Staphylococcus aureus bacteria, and the obtained results exhibited a promising antibacterial activity of the as-synthesized nanoparticles.

Keywords Silver nanoparticles - Ionomer cement · Vickers hardness - Monsanto hardness - Antibacterial activity

\section{Introduction}

The fascinating size of $1-100 \mathrm{~nm}$ is dealt with nanotechnology which has gained a wider interest in the research field. Nanotechnology has become a useful tool in medical field for its extensive applications in several forms. Metal nanoparticles are always enhanced for their unique properties and potential applications in the engineering and 
medical field. Among the various metal nanoparticles noble metal nanoparticles such as silver nanoparticles (AgNPs) were of great importance due to their distinctive physical and chemical properties. Recently the study of AgNPs is concentrated due to their antibacterial activity (Kim et al. 2007; Shahverdi et al. 2007) and dental applications (García-Contreras et al. 2011). AgNps are also used in various applications such as nanosensors due to their excellent electrochemical properties (Manno et al. 2008), halloysite nanotubes (HNTs) (Liu and Zhao 2009), catalyst (Guo et al. 2008), textile industry, water treatment (Dankovich and Gray 2011) optical data storage (Kelly et al. 2003), fluorescent emissions in biological labels and electroluminescent displays (Mulvaney 1996; Berciaud et al. 2005).

Glass ionomers (GI) were an important adhesion of restorative materials in restorative dentistry. The glass ionomer cement (GIC) is composed of acid and base, i.e., calcium, strontium aluminosilicate glass powder (base) combined with a water-soluble polymer (acid) such as aqueous solution of an acrylic acid homo- or copolymer. This glass ionomer cement finds a wider area of applications due to its unique properties and is used as base metals in restorative and adhesive to tooth structure. They are also used for its anticarcinogenic, thermal compatibility and biocompatibility properties. The invention of glass ionomer cement replaced the conventional cements made of phosphoric and silicate in dental medicine. GIC finds numerous applications in dentistry medicine such as to treat luting crowns, bridges, esthetic restorative cement, reinforced restorative cement and lining cement. They provide toothcolored restorations with low technique sensitivity and bond chemically to fix the decayed tooth and release levels of fluoride that protect cavosurface margins from recurrent caries attack (Knight 2016). The main disadvantages of the GICs are it is not recommended for biting surfaces in permanent teeth, the aging of the GIC results in poor wear and cracks over time and also accumulates plaque and periodontics diseases due to accumulation of bacteria commonly known as secondary caries.

Secondary caries are the most vulnerable caries raised out after different dental restoration treatments and the most commonly raised after fixing the caries or tooth decays with GIC. The placement of restorations can lead to the development of environmental conditions favorable to microbial colonization, especially on the tooth/restoration interface, which is a predisposing factor for secondary caries (Pedrini et al. 2001).

In the present work, the AgNps were synthesized using a novel green synthesis technique (Kouvaris et al. 2012). Various other synthesis techniques have also been reported for the preparation of metal silver nanoparticles such as laser ablation (Bae et al. 2002), microwave-polyol (Patel et al. 2005a, b), sonochemical (Salkar et al. 1999; Zhang et al. 2006), sonoelectrochemical (Liua et al. 2001), microwave dielectric heating (Patel et al. 2005a, b) solvothermal (Rosemary and Pradeep 2003) and electrochemical (Starowicz et al. 2006) synthesis techniques. Most of these conventional physical and chemical nanoparticle synthesis techniques results in the usage of toxic chemicals and are expensive. Efforts are being made to develop environmentally friendly synthesis techniques to fabricate nanoparticles (Hubenthal (2011). Some of the most important fabrication techniques of green synthesis are achieved through bio-organisms, plant leaves and fruit extracts (Ghodake et al. 2010). Cost efficiency, fast and low risks of toxicity are the important advantages of green synthesis (Sanghi and Verma 2009).

To the best of our knowledge there are no reports on the green-synthesized Ag nanoparticles from Magnifera Indica leaves which are used for dual, i.e., antimicrobial and dental restoration application at a single instance. In the present work, AgNPs were prepared by a novel green synthesis technique. Sumit Kumar et al., Martínez-Bernett et al. and Vikas Sarsar et al. used the green synthesis technique to produce the silver nanoparticles. Sumit Kumar et al. worked on the synthesis of silver nanoparticle using a combination of Magnifiera indica and Syzygium cumini leaf extracts. Martínez-Bernett et al. and Vikas Sarsar et al. also presented the synthesis of silver nanoparticles from Magnifiera indica leaf extracts, but they did not project the antimicrobial activity or the usage of dental restoration applications using the prepared silver nanoparticles (Contreras et al. 2015; Martínez-Bernett et al. 2016; Kumar et al. 2013, Sarsar et al. 2013; Philip 2011). In the present work, we elevated the combinational, i.e., dual application of the silver nanoparticles as an antimicrobial agent and even for the dental restoration. Their structural properties are reported by spectroscopic characterization such as Particle Size Analyzer (PSA), Powder X-ray diffraction (PXRD), Scanning Electron Microscope (SEM), Energydispersive X-ray analysis (EDS) and UV-Vis spectroscopy. The as-synthesized AgNPs were reinforced with glass ionomer cement to improve the mechanical bonding strength. The Stokes Monsanto hardness and Micro Vickers Hardness tests were performed on GIC, GIC reinforced with microsilver particles and GIC reinforced with AgNPs. The antimicrobial activity of the prepared AgNPs was tested on E. coli and $S$. aureus bacterial species.

The eventual rational of the present work is to synthesis a clean and eco-friendly, economic and tranquil bulk silver nanoparticle. These prepared silver nanoparticles were used in a two-way dental restoration application simultaneously. As previously mentioned, the dentistry medication with glass ionomer cement finds a major limitation in poor wear and secondary caries raised out of accumulation of 
bacterial colonies around the restoration using GIC at an early or aging state. The prepared silver nanoparticles were reinforced with glass ionomer cement to meet the said two limitations simultaneously. The reinforcement of AgNPs in GIC provides the enhancement in the hardness of conventional GIC and similarly resolves the limitation secondary caries raised of bacterial colonies around the GIC fixed restoration in post-medication. The enhancement of hardness of AgNP-reinforced GIC is compared with conventional GIC and microsilver-reinforced GIC and the antimicrobial activity of AgNPs is performed on Escherichia coli and Staphylococus aureus bacteria.

\section{Experimental procedure}

Silver nanoparticles were synthesized by a novel green synthesis technique (Knight 2016). Fresh Mangifera indica (Mango leaves) were collected from the mango garden at Jawaharlal Nehru Technological University Kakinada, India and silver nitrate $\left(\mathrm{AgNO}_{3}\right)$ was purchased from Merck chemicals, India. All the chemicals used in the production were of analytical grade and are of above $99 \%$ purity. These fresh mango leaves were washed thoroughly with distilled water, chopped into small pieces and air dried, respectively. About $15 \mathrm{gm}$ of air dried leaf was weighed on a digital balance and mixed thoroughly with $60 \mathrm{ml}$ of distilled water in a $250-\mathrm{ml}$ beaker and boiled at $100{ }^{\circ} \mathrm{C}$ for $25 \mathrm{~min}$. The extract obtained was cooled and filtered through Whatman No. 1 paper and the filtrate was collected in a 250-ml Erlenmeyer flask and stored in refrigerator for further use. In the typical synthesis of AgNPs, the leaf extract of $1.5 \mathrm{ml}$ was added to $30 \mathrm{ml}$ of $10^{-3} \mathrm{M} \mathrm{AgNO}_{3}$ solution in a $250-\mathrm{ml}$ Erlenmeyer flask and heated on water bath at $75{ }^{\circ} \mathrm{C}$ for $1 \mathrm{~h}$. Reduction of silver nitrate to silver ions was confirmed by the change in color of the prepared colorless solution to brown solution. The fully reduced solution was centrifuged at $2000 \mathrm{rpm}$ for $30 \mathrm{~min}$. The supernatant liquid was discarded and the viscous silver remnant was collected and applied over a Whatman No. 1 paper and left for $48 \mathrm{~h}$. Now the dried silver nanoparticles were collected. Hence, AgNps were successfully synthesized.

\section{Hardness test specimens}

The glass ionomer cement of type 9 (GIC 9) is blended with $3 \%$ weight ratio (Contreras et al. 2015) of the prepared face-centered cubic AgNPs and microsilver particles separately in a vortex for $2 \mathrm{~min}$. Three different compounds were prepared in Teflon medium as GIC, GIC (3.4gms) reinforced 3\% (w/w) $(0.1 \mathrm{~g})$ microsilver particles and GIC $(3.4 \mathrm{~g})$ reinforced 3\% (w/w) $(0.1 \mathrm{~g})$ AgNPs.
According to the American Dental Association (ADA) specification, 27 of these samples were prepared as $9.5 \times 1 \mathrm{~mm}$ cylinder specimens Contreras et al. 2015) to undergo the Monsanto hardness and Vickers microhardness tests.

\section{Antibacterial assays}

The antibacterial effect of AgNPs was evaluated by standard diffusion technique or Kirby-Bauer methods (Sanghi and Verma 2009). Kirby-Bauer and Stokes methods are generally used for antibacterial testing. The most accepted antimicrobial susceptibility testing by Clinical and Laboratory Standards Institute (CLSI) is Kirby-Bauer method (Martínez-Bernett et al. 2016). $500 \mu \mathrm{l}$ of microbial cultures of age 18-24 h were inoculated into Petri plates in nutrient agar medium and solidified. AgNPs were suspended in the four different holes as shown in Fig. 1 in four different concentrations of 2, 4, 6 and $8 \mu \mathrm{g} / \mathrm{ml}$. These plates were wrapped with a parafilm tape and incubated for $24 \mathrm{~h}$ at $35{ }^{\circ} \mathrm{C}$.

\section{Characterization}

The $\mathrm{VASCO}^{\mathrm{TM}}$ nanoparticle size analyzer (PSA) was performed for nanoparticle characterization, based on the Dynamic Light Scattering (DLS) at $135^{\circ} \mathrm{C}$. Powder X-ray diffraction (PXRD) analysis were performed on a PANalytical XPert Pro-diffractometer equipped with Ni filter

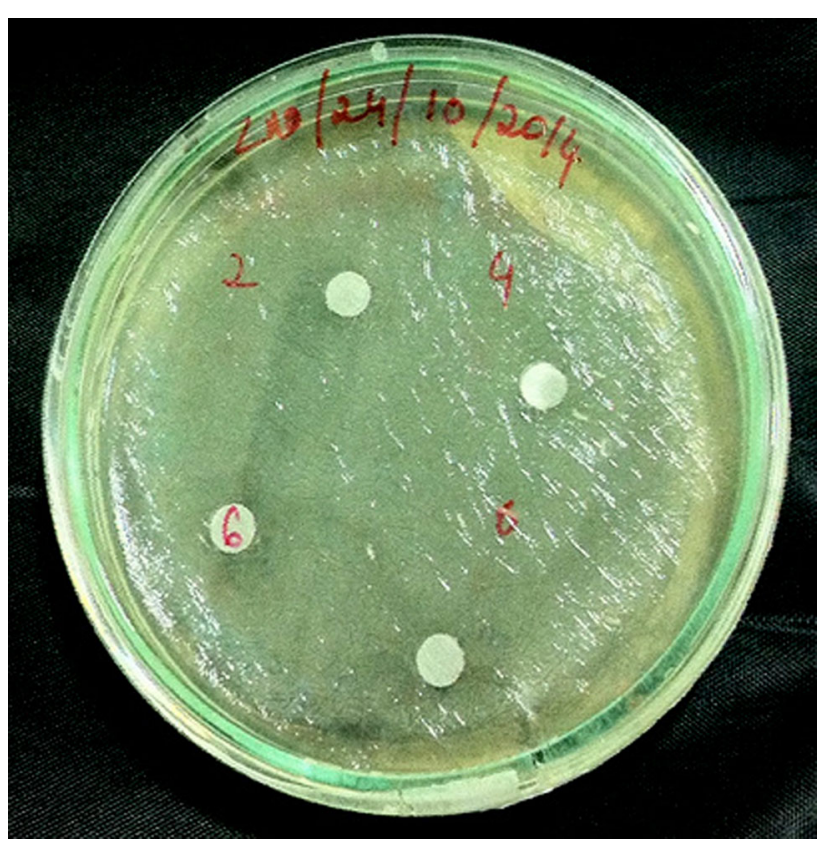

Fig. 1 Escherichia coli Petri plates with Ag nanoparticles at different concentrations 
with $\mathrm{CuK} \alpha$ radiation $(\lambda=1.5406 \AA)$. The measurements were made at room temperature at a range of $10^{\circ}-80^{\circ}$ on $2 \theta$ with a step size of $0.05^{\circ}$ in $40 \mathrm{keV}$ at $15 \mathrm{mV}$ applied current. Scanning electron microscope (SEM) images were obtained from a Carl Zeiss SEM EVO with carbon coating and energy-dispersive X-ray spectroscopy (EDS) images were taken from ZEISS EVO 18. Prepared powder sample was mixed with Nujol (liquid paraffin) mull form to record the optical absorption spectrum, and recorded on JASCO V-670 Spectrophotometer in region of 200-1400 nm wavelength at room temperature. Optical microscopic images of ionomer cement along with reinforced microand nanosilver particles were taken on Olympus BX61 digital microscope. The hardness of these samples was analyzed by HVS-1000Z Digital Micro Vickers Hardness Tester with 25 gram of load weight and Dolphin Stokes Monsanto hardness tester.

\section{Results and discussion}

\section{Particle size analysis}

The prepared AgNPs were suspended in low-concentrated ethyl alcohol and ultrasonicated for $10 \mathrm{~min}$. The prepared sample was subjected $245 \mathrm{~nm}$ laser wavelength in particle size analyzer spectroscopy. Figure 2 shows the PSA graph of AgNPs. The synthesized AgNPs exhibit a mean particle size of $31.7 \mathrm{~nm}$ under the dynamic light scattering. The crystalline size calculated from PSA is further counterverified by PXRD and Williamson-Hall plots.

\section{X-ray diffraction analysis}

The X-ray diffraction is performed to estimate the crystal structural phase of the synthesized AgNPs. The XRD graph of AgNPs is as shown in Fig. 3. The diffraction peaks of AgNPs exhibit face-centered cubic $(\mathrm{cF})$ crystal system with corresponding lattice parameters as $a=4.070 \mathrm{~nm}$. All the diffraction peaks of the AgNPs are well matched with the

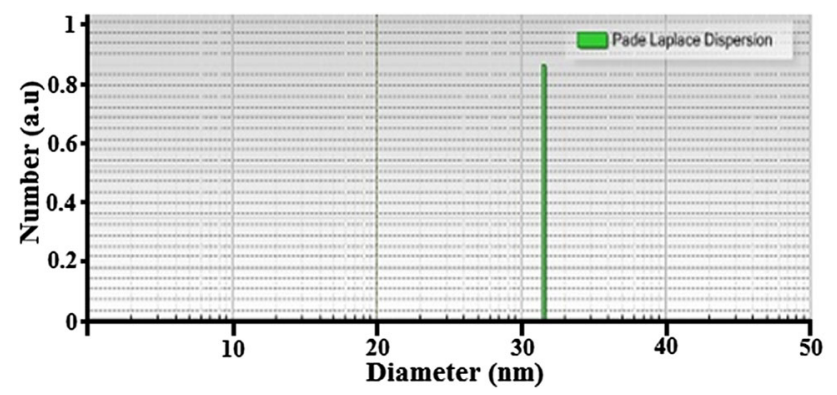

Fig. 2 Particle size analyzer graph of Ag nanoparticles

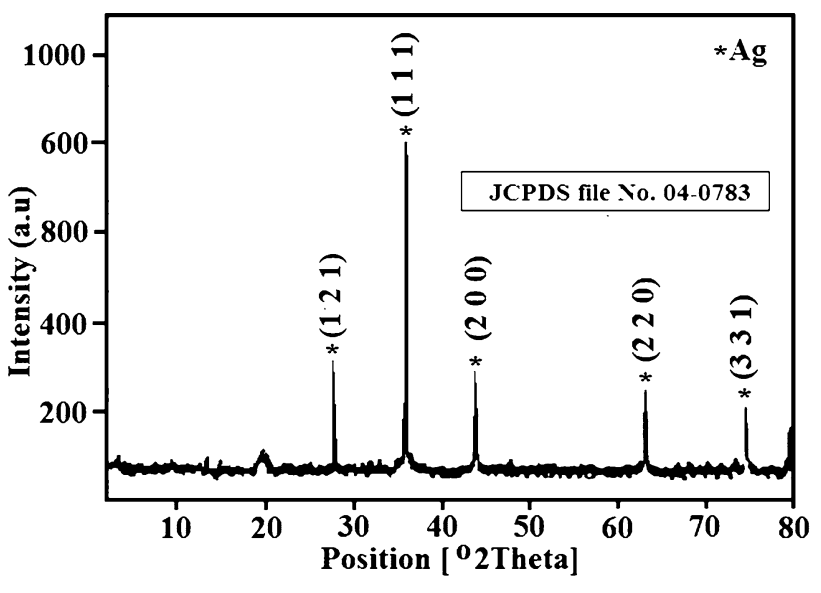

Fig. 3 X-ray diffraction patterns of Ag nanoparticles

standard diffraction data of JCPDS file No. 04-0783 for face-centered cubic Ag.

The existence of sharp peaks of $2 \theta$ located at $38.25^{\circ}$, $44.12^{\circ}, 64.27^{\circ}$ and $77.52^{\circ}$ corresponding to (111), (200), (220) and (331) planes indicates the formation of pure silver nanoparticles. X-ray diffraction is a powerful tool used to estimate the crystalline size, lattice strain and dislocation densities. The average crystalline size of the prepared samples was calculated using the Debye-Scherrer's formula given in the following equation (Sundeep et al. 2016; Gopala Krishna et al. 2016; Ravikumar et al. 2016)

$D=\frac{0.9 \lambda}{\beta \cos \theta} \mathrm{nm}$

where ' $D$ ' is the crystalline size; $\lambda$ is the wavelength of $\mathrm{X}$-ray $(\lambda=0.154056 \mathrm{~nm}$ for $(\mathrm{CuK} \alpha) ; \beta$ is the full width at half maximum (FWHM) of the Braggs peak (in radians); $\theta$ is the diffraction angle of the reflection.

From Eq. (1) the crystalline size is calculated as $32.3 \mathrm{~nm}$, respectively. There is negligible increase in the crystalline size from XRD data in comparison to PSA. The sharp peaks assume the formation of pure sample with no evidence of any bulk remnants or impurities. Microstrain is a measurement of distribution of lattice constants arising from crystal imperfection such as lattice dislocation. The slight peak broadening in the XRD graph as shown in Fig. 3 indicates the presence of small microstrains in the sample. The microstrain ( $\varepsilon$ )-induced broadening in the powders are due to crystal imperfection and distortion which is calculated using the following equation (Gopala Krishna et al. 2016, Ravikumar et al. 2016).

$\varepsilon=\frac{\beta \cos \theta}{4}$

$\mathrm{X}$-ray line broadening was used to estimate the dislocation densities in the samples. The dislocation density $(\delta)$ was calculated using the following equation: 
$\left(\delta=1 / D^{2}\right)$

where $D$ is the crystallite size.

Williamson-Hall analysis is a simplified integral breadth method employed for estimating crystal, crystallite size and lattice strain, considering the peak width as a function of $2 \theta$ (Sundeep et al. 2016). The crystallite size is not necessarily the same as particle size, since the crystallite size is assumed to be the size of a coherently diffracting domain. From Eqs. (1) and (2), it is clear that the peak width from crystalline size varies as per the equation $\frac{1}{\cos \theta}$ and strain takes the equation $\tan \theta$. Assuming the particle size and the strain contributions to line broadening are independent of each other and both have Cauchy-like profile, the observed line breadth is taken as the sum of Eqs. (1) and (2),

$\beta=\frac{0.9 \lambda}{D \cos \theta}+4 \varepsilon \tan \theta$

By rearranging Eq. (4), we get

$\beta \cos \theta=\frac{0.9 \lambda}{D}+4 \varepsilon \sin \theta$

Equation (5) is the Williamson-Hall equation (Sundeep et al. 2016), which assumes that the strain is uniform in all crystallographic directions. W-H equation represents a straight line between the $4 \sin \theta$ ( $X$-axis) and $\beta \cos \theta$ ( $Y$-axis). The crystallite size $(D)$ and microstrain $(\varepsilon)$ are calculated from the intercept $(k \lambda / D)$ and slope of the line. Figure 4 shows the $(\mathrm{W}-\mathrm{H})$ plots of AgNPs. Table 1 shows the comparison of average crystalline size, lattice strain and dislocation density of the AgNPs. The crystalline sizes from particle size analyzer (PSA), Debye-Scherrer's and microstrains calculated are compared with the calculations of $\mathrm{W}-\mathrm{H}$ plots, and are found to be closely matched.

\section{Morphological studies}

The morphological studies of the prepared samples are observed by scanning electron microscopy analysis. To analyze the morphology, SEM is considered as an important technique (Sundeep et al. 2016). Figure 5 shows the SEM graphs of the Ag nanoparticles. SEM graphs reveal the flake-like structures of the synthesized AgNPs. The

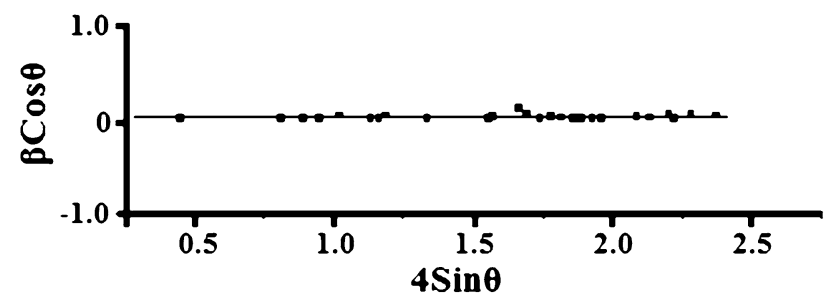

Fig. 4 Williamson-Hall plot of Ag nanoparticles energy-dispersive X-ray spectra of AgNPs are shown in Fig. 6. The EDS spectroscopy is a potential tool used to reveal the elemental constituents. From the Fig. 6 it is clearly shown that the prepared sample is composed of $\mathrm{Ag}$ (silver) and $\mathrm{O}$ (oxygen). No other elemental impurity was found in EDS which strengths the purity of the sample.

\section{Optical studies}

The optical properties of the synthesized AgNPs were analyzed by UV-Visible absorbance spectroscopy. The UV-Vis absorption spectrum of AgNPs is as shown in Fig. 7. Measuring the band gap is an important parameter in the nanomaterial industry. To analyze the conductivity of the synthesized nanomaterial, the term band gap refers to the energy difference between the top of the valency band and bottom of the conduction band which are able to jump from one band to another. For an electron to jump from a valence band to conduction band it requires a specific minimum amount of energy for the transition called as band energy. Based on the band gap energies the materials can be classified as insulators $(>4 \mathrm{eV})$ and semiconductors $(<3 \mathrm{eV})$. The optical edge of AgNPs nanoparticles is observed at $393 \mathrm{~nm}$, which is a typical absorption band of face-centered cubic AgNPs (Alan Creighton et al. 1979). The band gap energy is calculated as $4.9 \mathrm{eV}$ by the following Planck's equation (Ma et al. 2015).

Band Gap Energy $(E)=h \times C / \lambda$

where $h$ is the Planck's constant $=6.626 \times 10^{-34} \mathrm{~J} \mathrm{~s}, C$ is the speed of light $=3 \times 10^{8} \mathrm{~m} / \mathrm{s}$, and $\lambda$ is the cutoff wavelength $=393 \times 10^{-9}$.

\section{Dental and antimicrobial applications of AgNPs}

In this part the green-synthesized AgNPs were reinforced with Glass ionomer cement (GIC) and the mechanical bonding enhancement was tested and compared with conventional and micro- and nanosilver particle-reinforced GIC. To analyze the antibacterial activity, AgNPs were tested on E. coli and S. aureus bacterial species.

\section{Dental application}

Recently silver compounds and nanoparticles are studied for their vast area of research in dental applications such as dental restorative material, endodontic retro fill cement, dental implants and caries inhibitory solutions (Jia et al. 2008; Pissiotis and Spngberg 2000; Sheikh et al. 2010; Swift 1989). Glass ionomer cement (GIC) is known for its adhesiveness and biocompatibility; therefore, it is used as restorative material in dentistry (Pereira et al. 2002; 
Table 1 Average crystallite size, lattice strain and dislocation densities of Ag nanoparticles

\begin{tabular}{lllllll}
\hline Sample & \multicolumn{2}{l}{ Crystalline size $(\mathrm{nm})$} & & Microstrain $\left(\varepsilon \times 10^{-3}\right)$ & Dislocation density $\left(\delta \times 10^{-15} \mathrm{~m}^{-2}\right)$ \\
\hline Silver nanoparticles & PSA & Scherrer's & W-H method & Calculated & W-H method & Scherrer's \\
& 31.7 & 32.4 & 33.21 & 0.21 & 0.29 & 1.642 \\
\hline
\end{tabular}

Fig. 5 SEM images of $\mathrm{Ag}$ nanoparticles
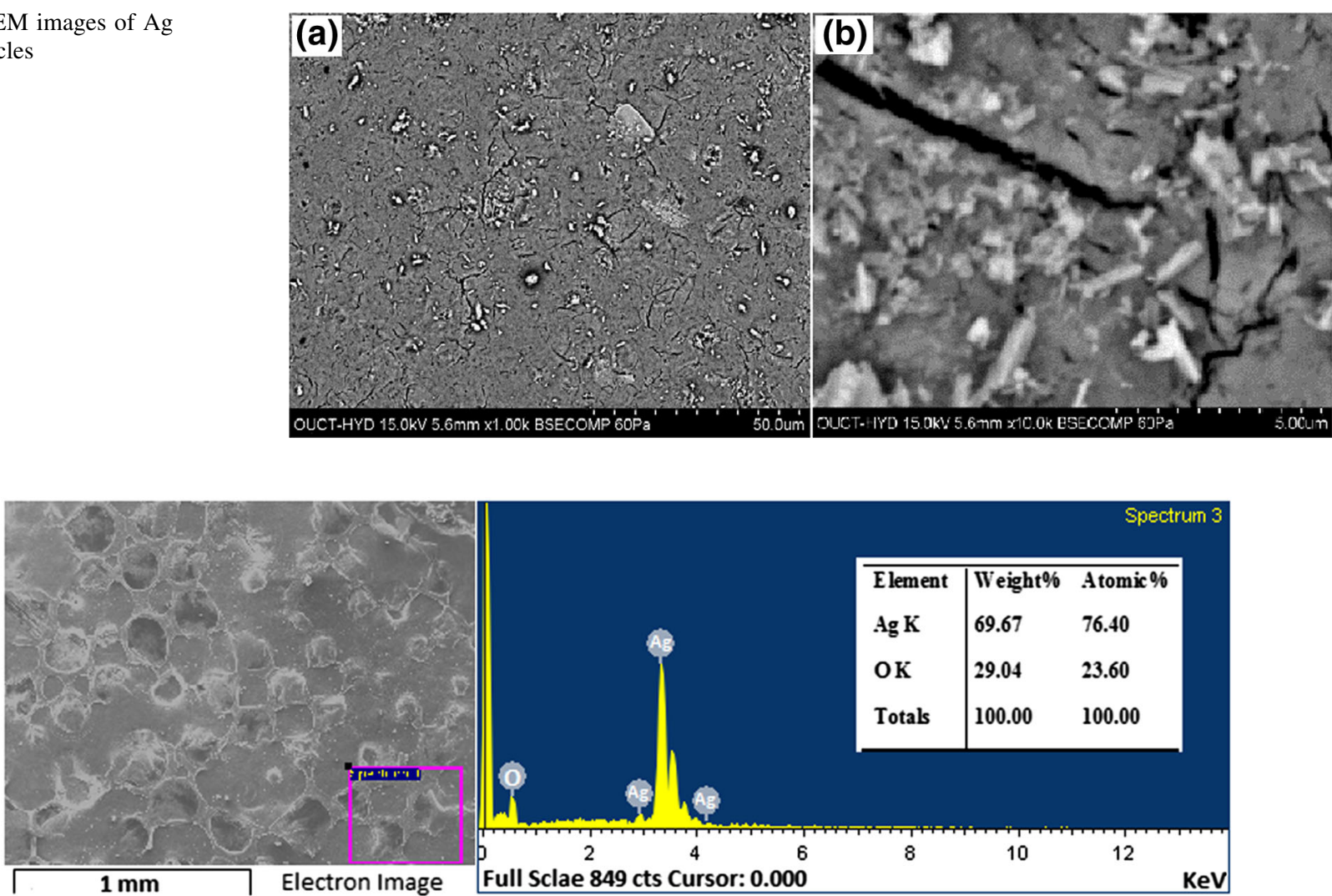

Fig. 6 EDS pattern of $\mathrm{Ag}$ nanoparticles

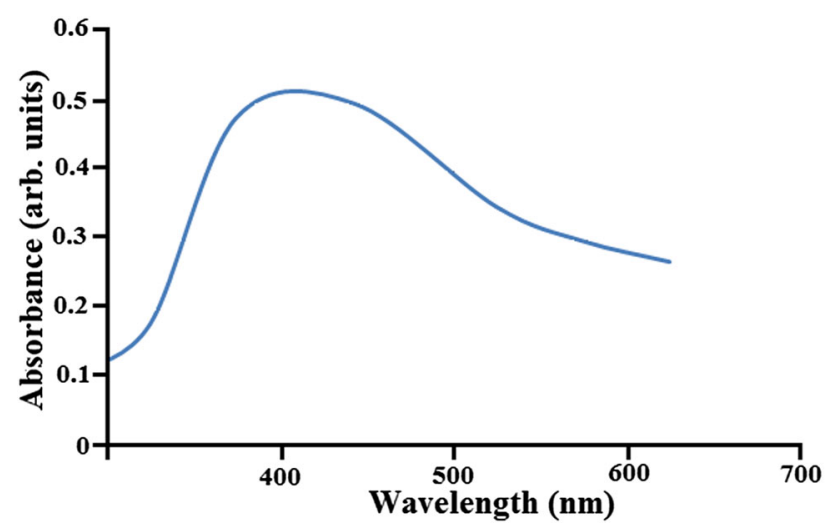

Fig. 7 UV-Vis spectra of Ag nanoparticles

Brentegani et al. 1997). Low wear resistance and facture toughness are the major disadvantages which result in the failure of restoration and leads to growth of bacterial proliferation. These failures can even lead to ancillary caries and tooth fracture. Extensive research had been done to overcome these failures and enhance the mechanical properties and bonding nature of GIC. Silver-amalgam particles, zirconia, spherical silica are some of the promising notable fillers reinforced with GIC to improve mechanical properties of GIC (Contreras et al. 2015).

The microscopic images of GIC, GIC-reinforced microsilver particles and GIC-reinforced nanosilver particles are as shown in Fig. 8. The above-prepared compounds are divided into five samples and the mechanical hardness is tested by Monsanto and Vickers hardness tests. Hardness is the property of a material that enables it to resist plastic deformation, usually by penetration. Monsanto hardness tester consists of a barrel containing a compressible spring held between two plungers. The lower plunger is placed in contact with the tablet with a zero reading and the upper plunger is then forced against a spring by knurling the knob. The hardness is recorded in $\mathrm{kg} / \mathrm{sq} . \mathrm{cms}$ on 
Fig. 8 a-c Microscopic images of GIC, GIC-reinforced silver microparticles and GICreinforced silver nanoparticles

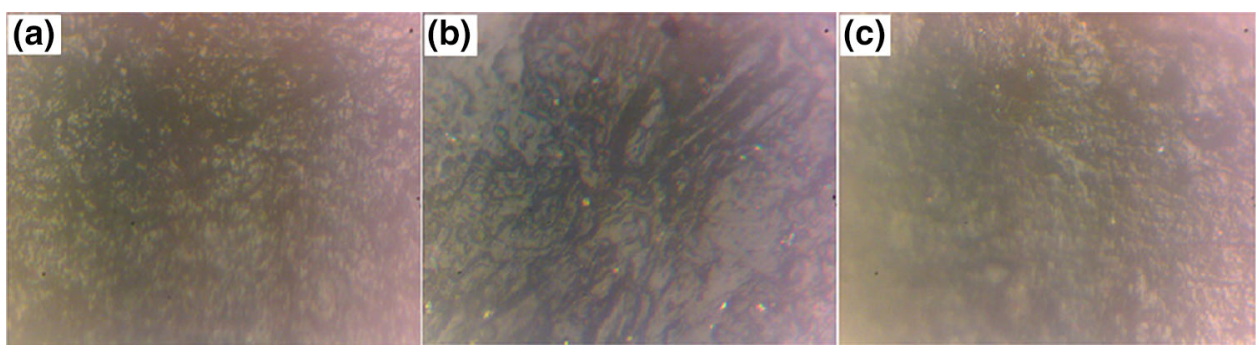

Table 2 Monsanto and Vickers hardness values of GIC, GIC-reinforced microsilver particles and GIC reinforced with silver nanoparticles

\begin{tabular}{|c|c|c|c|c|c|c|}
\hline \multirow[t]{3}{*}{ S. no. } & \multicolumn{6}{|l|}{ Hardness test } \\
\hline & \multicolumn{2}{|l|}{ GIC } & \multicolumn{2}{|c|}{ GIC reinforced with silver microparticles } & \multicolumn{2}{|c|}{ GIC reinforced with silver nanoparticles } \\
\hline & Monsanto $\left(\mathrm{kg} / \mathrm{cm}^{2}\right)$ & Vickers (VHN) & Monsanto $\left(\mathrm{kg} / \mathrm{cm}^{2}\right)$ & Vickers (VHN) & Monsanto $\left(\mathrm{kg} / \mathrm{cm}^{2}\right)$ & Vickers (VHN) \\
\hline 1 & 9.5 & 69 & 11.7 & 54 & 13.7 & 79 \\
\hline 2 & 10.5 & 51 & 12.3 & 66 & 15.0 & 86 \\
\hline 3 & 9.2 & 47 & 11.5 & 62 & 14.5 & 79 \\
\hline 4 & 8.7 & 51 & 10.8 & 64 & 13.0 & 82 \\
\hline 5 & 9.5 & 52 & 12.5 & 59 & 14.7 & 84 \\
\hline Average & 9.5 & 54 & 11.7 & 61 & 14.2 & 82 \\
\hline
\end{tabular}

breaking the pellet. The obtained Monsanto hardness results are tabulated in Table 2. Significant increase of mechanical bonding strength is achieved with AgNP-reinforced GIC. The Vickers microhardness test is the most sensitive test than Monsanto hardness test (Contreras et al. 2015). The aboveprepared specimens were tested on diamond indenter with $25-\mathrm{g}$ load weight. The results are tabulated in Table 2 and an improved mechanical bonding strength is observed with AgNP-reinforced specimens. The results were compared and are shown in Fig. 9.

\section{Antibacterial activity}

Silver ions show high biocidal effects on twelve different types of bacteria which include E. coli and S. aureus (Zhao and Stevens 1998). Even though the proper reasons for the antibacterial activity of AgNPs were not explained, Sondi, Salopek-Sondi et al. and Hamounda et al. explained the antibacterial effect of AgNPs as the electrostatic attraction between positively charged AgNPs and negatively charged bacteria (Sondi and Salopek-Sondi 2004; Sharma et al. 2009). Figure 10 shows the antibacterial effect of 2, 4, 6 and $8 \mu \mathrm{g} / \mathrm{ml} \mathrm{AgNPs}$ on E. coli and S. aureus bacteria. More than $90 \%$ of the bacteria were inhibited by the presence of AgNPs. The inhibition zones were recorded in millimeters and are tabulated in Table 3 and are shown in Fig. 11. From Fig. 10 it is clearly shown that the suspended AgNPs inhibit the growth and reproduction of bacterial cells. It is clearly visible that after $24 \mathrm{~h}$ of inhibition almost all the bacterial cells were found dead and formed a layer around the AgNP

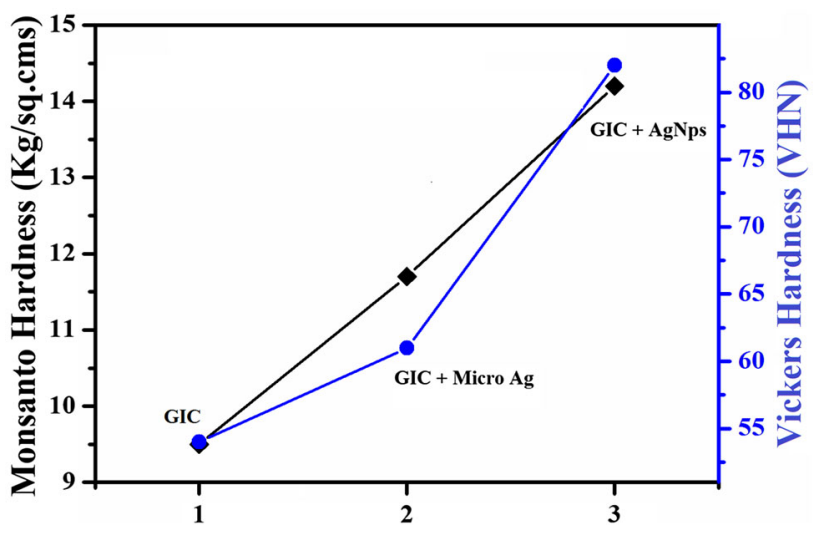

Fig. 9 Graph comparing the average results of Monsanto and Vickers hardness tests

pits in the Petri plates. The antibacterial activity of $2 \mu \mathrm{g} / \mathrm{ml}$ AgNPs was slightly slower than the other concentrations. From the concentration vs. inhibition graph (Fig. 11) the inhibition activity was ascending on increasing the concentration of AgNPs. Hence, this experiment can be considered for the usage of a controlled level of inhibition.

\section{Conclusion}

In this work, silver nanoparticles were synthesized by a novel green synthesis technique using fresh Mangifera indica (mango leaves) and characterized to evaluate the crystalline size, shape, crystalline imperfection and 
Fig. 10 Antimicrobial activity of Ag nanoparticles at different concentrations against Escherichia coli and Staphylococcus aureus

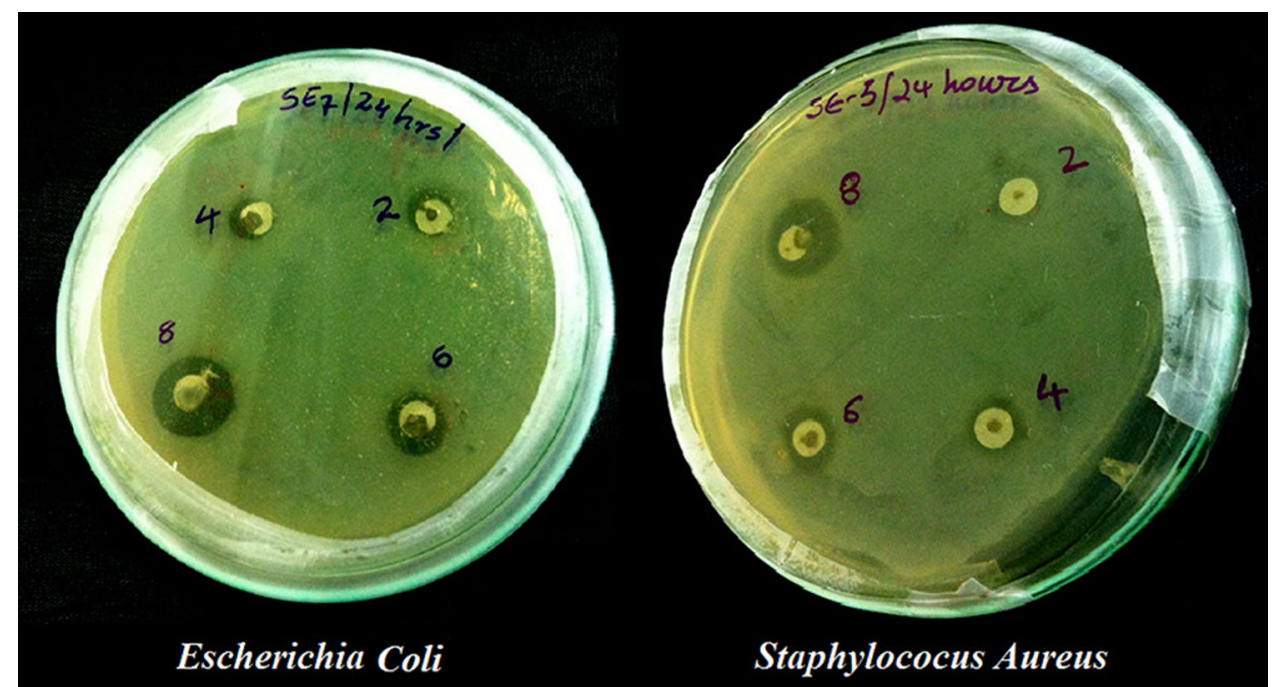

Table 3 Change of inhibition of Escherichia coli and Staphylococcus aureus with the concentration of AgNPs

\begin{tabular}{lllll}
\hline Concentration of AgNPs & $2 \mu \mathrm{g} / \mathrm{ml}$ & $4 \mu \mathrm{g} / \mathrm{ml}$ & $6 \mu \mathrm{g} / \mathrm{ml}$ & $8 \mu \mathrm{g} / \mathrm{ml}$ \\
\hline Inhibition zone of Escherichia coli $(\mathrm{mm})$ & 0.5 & 0.7 & 0.9 & 1.2 \\
Inhibition zone of Staphylococcus aureus $(\mathrm{mm})$ & 0.7 & 0.9 & 1.1 & 1.5 \\
\hline
\end{tabular}

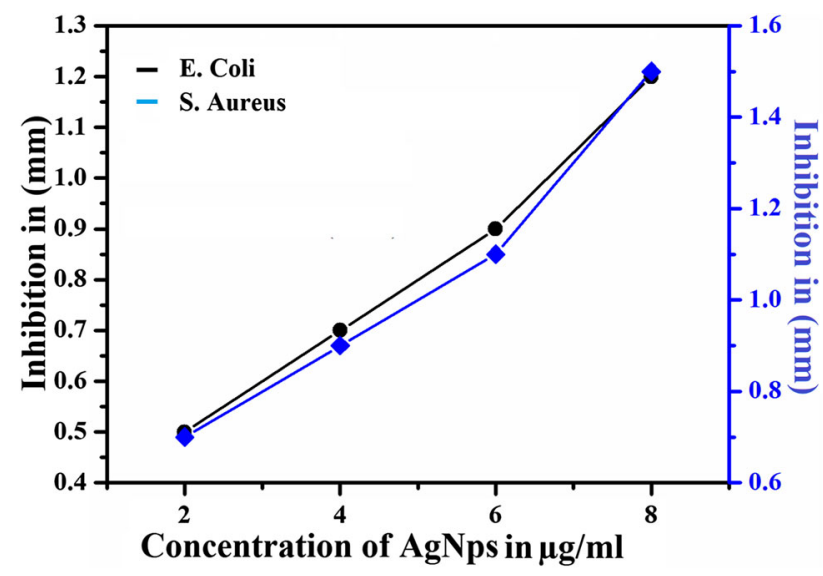

Fig. 11 Zone of inhibition (mm) shown by AgNPs at different concentration

distortions, dislocation density. The crystalline size was evaluated from PXRD using the Scherrer's formula and particle size analyzer. Both of the analysis evaluated the crystalline size as $32 \pm 2 \mathrm{~nm}$. The crystalline size was also evaluated theoretically using the Williamson-Hall plots and obtained the same crystalline size resulted from the PXRD and PSA analysis. The morphological studies were evaluated from the SEM images which confirm the nanoscale size of the synthesized particle. The EDS spectra showed the elemental composition of the prepared AgNPs and determined the purity of the sample. Optical studies were performed to evaluate the band gap energy and that was found to be $393 \mathrm{~nm}$, which relates to the absorption band of face-centered cubic silver nanoparticles.
The Glass Ionomer Cement (GIC) was reinforced with as-synthesized AgNPs to obtain an enhanced dual dentistry application (improving the low wear of the conventional GIC and on the other hand, preventing the formation of bacterial colonies in the medicated part of the teeth). The Vickers microhardness test and Monsanto hardness test were performed on AgNP-reinforced GIC and the obtained results were compared with those of conventional GIC and GIC-reinforced microsilver particles. Results clearly showed the enhanced hardness of the AgNP-reinforced GIC. The antibacterial activity of the synthesized silver nanoparticles against Escherichia coli and Staphylococcus aureus bacteria was evaluated at different concentrations and reasonable antibacterial activity of the AgNPs was obtained. Accordingly, the present study suggests dual simultaneous dentistry applications of the synthesized AgNPs.

Acknowledgements One of the authors Dola Sundeep is thankful to the Director of Centralized Laboratory, Department of Physics, Acharya Nagarjuna University, Guntur, for his guidance, encouragement and for providing the XRD. Department of Biotechnology, JNTU Kakinada is acknowledged for providing UV-Vis. Osmania College of Technology (OUCT) for providing SEM and EDS and is also thankful to AICTE, New Delhi, India, for providing financial assistance through AICTE-GATE meritorious fellowship (11889699051).

\section{Compliance with ethical standards}

Funding information The present work was funded by All India Institute of Technical Education (AICTE)-GATE meritorious fellowship, Grant No. (1-1889699051). 
Conflict of interest All authors declare that they do not have any financial or any other conflict of interest/s.

Ethical approval No animals or humans were used in the present work.

Open Access This article is distributed under the terms of the Creative Commons Attribution 4.0 International License (http://crea tivecommons.org/licenses/by/4.0/), which permits unrestricted use, distribution, and reproduction in any medium, provided you give appropriate credit to the original author(s) and the source, provide a link to the Creative Commons license, and indicate if changes were made.

\section{References}

Alan Creighton J, Blatchford CG, Grant Albrecht M (1979) Plasma resonance enhancement of Raman scattering by pyridine adsorbed on silver or gold sol particles of size comparable to the excitation wavelength. J Chem Soc Faraday Trans 2(75):790-798. doi:10.1039/F29797500790

Bae CH, Nam SH, Park SM (2002) Formation of silver nanoparticles by laser ablation of a silver target in $\mathrm{NaCl}$ solution. Appl Surf Sci 197:628-634. doi:10.1016/S0169-4332(02)00430-0

Berciaud S, Cognet L, Tamarat P, Lounis B (2005) Observation of intrinsic size effects in the optical response of individual gold nanoparticles. Nano Lett 5(3):515-518. doi:10.1021/n1050062t

Brentegani LG, Bombonato KF, Carvalho TL (1997) Histological evolution of the biocompatibility of glass-ionomer cement in rat alveolus. Biomaterials 18:137-140

Contreras RG, Scougall-vilchis RJ, Contreras-bulnes R, Sakagami H, Morales-luckie RA, Nakajima H (2015) Mechanical, antibacterial and bond strength properties of nano-titanium-enriched glass ionomer cement. J Appl Oral Sci 23(3):501-504. doi:10.1590/ 1678-775720140496

Dankovich TA, Gray DG (2011) Bactericidal paper impregnated with silver nanoparticles for point-of-use water treatment. Environ Sci Technol 45(5):1992-1998. doi:10.1021/es103302t

García-Contreras R, Argueta-Figueroa L, Mejía-Rubalcava C, Jiménez-Martínez R, Cuevas-Guajardo S, Sánchez-Reyna PA, Zeron HM (2011) Perspectives for the use of silver nanoparticles in dental practice. Int Dent J 61:297-301. doi:10.1111/j.1875595X.2011.00072.x

Ghodake GS, Deshpande NG, Lee YP, Jin ES (2010) Pear fruit extract-assisted room-temperature biosynthesis of gold nanoplates. Colloids Surf B 75:584-589. doi:10.1016/j.colsurfb.2009. 09.040

Guo JZ, Cui H, Zhou W, Wang W (2008) Ag nanoparticle-catalyzed chemiluminescent reaction between luminol and hydrogen peroxide. J Photochem Photobiol A Chem 193:89-96. doi:10. 1016/j.jphotochem.2007.04.034

Hubenthal F (2011) Noble metal nanoparticles: Synthesis and applications. In: Andrews DL, Scholes GD, Wiederrecht GP (eds) Comprehensive nanoscience and technology, vol 1. Oxford Academic Press, New York, USA, pp 375-435

Jia H, Hou W, Wei L, Xu B, Liu X (2008) The structures and antibacterial properties of nano- $\mathrm{SiO}_{2}$ supported silver/zinc-silver materials. J Dent Mater 24(2):244-249. doi:10.1016/j.dental. 2007.04.015

Kim JS, Kuk E, Yu KN, Kim JH, Sung Jin Park, Lee HJ, Kim SH, Park YK, Park YH, Hwang CY, Kim YK, Lee YS, Jeong DH, Cho MH (2007) Antimicrobial effects of silver nanoparticles. Nanomed Nanotechnol Biol Med 1:95-101. doi:10.1016/j.nano. 2006.12.001
Knight GM (2016) The benefits and limitations of glass-ionomer cements and their use in contemporary dentistry. In: Sidhu SK (eds) Glass-ionomers in dentistry. Springer, Switzerland, pp 57-79. doi:10.1007/978-3-319-22626-2_3

Kouvaris P, Delimitis A, Zaspalis V, Papadopoulos D, Tsipas SA, Michailidis N, Lett M (2012) Green synthesis and characterization of silver nanoparticles produced using Arbutus Unedo leaf extract. Mater Lett 76:18-20. doi:10.1016/j.matlet.2012.02.025

Krishna AG, Ravikumar RVSSN, Kumar TV, Ephraim SD, Ranjith B, Pranoy M, Dola S (2016) Investigation and comparison of optical and Raman bands of mechanically synthesised $\mathrm{MoO} 3$ Nano powders. Mat Today Proc 3(1):54-63. doi:10.1016/j. matpr.2016.01.121

Kumar S, Saini J, Kashyap D, Batra B, Grewal A, Malik DK, Kumar R (2013) Green synthesis of plant-mediated silver nanoparticles using magnifera indica and syzygium cumini leaf extract. IJPSR. 3189

Lance Kelly K, Coronado E, Zhao LL, Schatz GC (2003) The optical properties of metal nanoparticles: the influence of size, shape, and dielectric environment. J Phys Chem B 107(3):668-677. doi:10.1021/jp026731y

Liu P, Zhao M (2009) Silver nanoparticle supported on halloysite nanotubes catalyzed reduction of 4-nitrophenol (4-NP) Appl. Surf Sci 255:3989-3993. doi:10.1016/j.apsusc.2008.10.094

Liua S, Huanga W, Chena S, Avivia S, Gedankena A (2001) J NonCryst Solids 283:231-236. doi:10.1016/S0022-3093(01)00362-3

Ma R, Sharma V, Baldwin AF, Tefferi M, Offenbach I, Cakmak M, Weiss R, Cao Y, Ramprasad R, Sotzing GA (2015) Rational design and synthesis of polythioureas as capacitor dielectrics. J Mater Chem A 3:14845-14852. doi:10.1039/C5TA01252J

Manno D, Filippo E, Di Giulio M, Serra A (2008) Synthesis and characterization of starch-stabilized Ag nanostructures for sensors applications. J Non-cryst Solids C 354:5515-5520. doi:10. 1016/j.jnoncrysol.2008.04.059

Martínez-Bernett D, Silva-Granados A, Correa-Torres SN, Herrera A (2016) Chromatographic analysis of phytochemicals components present in Mangifera indica leaves for the synthesis of silver nanoparticles by $\mathrm{AgNO}_{3}$ reduction. J Phys Conf Ser 687:012033

Mulvaney P (1996) Surface plasmon spectroscopy of nanosized metal particles. Langmuir 12(3):788-800. doi:10.1021/la9502711

Patel K, Kapoor S, Dave DP, Mukherjee T (2005a) Synthesis of Pt, $\mathrm{Pd}, \mathrm{Pt} / \mathrm{Ag}$ and $\mathrm{Pd} / \mathrm{Ag}$ nanoparticles by microwave-polyol method. J Chem Sci 117:311-316. doi:10.1007/BF02708443

Patel K, Kapoor S, Dave DP, Mukherjee T (2005b) Synthesis of nanosized silver colloids by microwave dielectric heating. J Chem Sci 117:53-60. doi:10.1007/BF02704361

Pedrini D, Junior GJ, Vasconcelos AC (2001) Retention of oral microorganisms on conventional and resin-modified glassionomer cements. Pesqui Odontol Bras. 15(3):196-200

Pereira LCG, Nunes MCP, Dibb RGP, Powers JM, Roulet JFrançois, Navarro MFL (2002) Mechanical properties and bond strength of glass-ionomer cements. J Adhes Dent 4(1):73-80

Philip D (2011) Mangifera indica leaf-assisted biosynthesis of welldispersed silver nanoparticles. Spectrochim Acta Part A Mol Biomol Spectrosc 78(1):327-331

Pissiotis E, Spngberg L (2000) Reaction of bony tissue to implanted silver glass ionomer and a reinforced zinc oxide-eugenol cement. Oral Surg Oral Med Oral Pathol Oral Radiol Endod 89:623-629. doi: $10.1067 /$ moe. 2000.105173

Ravikumar RVSSN, Sundeep D, Krishna AG, Ephraim SD, Ali A, Ahmed I, Manikanta KS, Kumar TV (2016) Spectral investigation of structural and optical properties of mechanically synthesized $\mathrm{TiO}_{2}-\mathrm{V}_{2} \mathrm{O}_{5}$ nanocomposite powders. Mat Today Proc 3(1):31-38. doi:10.1016/j.matpr.2016.01.114

Rosemary MJ, Pradeep T (2003) Solvothermal synthesis of silver nanoparticles from thiolates. J Colloid Interface Sci 268:81-84 
Salkar RA, Jeevanandam P, Aruna ST, Koltypin Y, Gedanken A (1999) The sonochemical preparation of amorphous silver nanoparticles. J Mater Chem 9:1333-1335. doi:10.1039/ A900568D

Sanghi R, Verma P (2009) Biomimetic synthesis and characterisation of protein capped silver nanoparticles. Bioresour Technol 100:501-504. doi:10.1016/j.biortech.2008.05.048

Sarsar V, Selwal KK, Selwal MK (2013) Green synthesis of silver nanoparticles using leaf extract of Mangifera indica and evaluation of their antimicrobial activity. J Microbiol Biotech Res 3(5):27-32

Shahverdi AR, Fakhimi A, Shahverdi HR, Minaian S (2007) Synthesis and effect of silver nanoparticles on the antibacterial activity of different antibiotics against Staphylococcus aureus and Escherichia coli. Nanomed Nanotechnol Biol Med 3:168-171. doi:10.1016/j.nano.2007.02.001

Sharma VK, Yngard RA, Lin Y (2009) Silver nanoparticles: green synthesis and their antimicrobial activities. J Colloid Interf Sci 145(1-2):83-96. doi:10.1016/j.cis.2008.09.002

Sheikh FA, Barakat NA, Kanjwal MA, Nirmala R, Lee JH, Kim H, Kim HY (2010) Electrospun titanium dioxide nanofibers containing hydroxyapatite and silver nanoparticles as future implant materials. J Mater Sci Mater Med 21(9):2551-2559. doi:10.1007/s10856-010-4102-9

Sondi I, Salopek-Sondi B (2004) Silver nanoparticles as antimicrobial agent: a case study on E. coli as a model for Gram-negative bacteria. J Colloid Interf Sci 275(1):177-182. doi:10.1016/j.jcis. 2004.02.012

Starowicz M, Stypuła B, Banaś J (2006) Electrochem Commun 8:230-277. doi:10.1016/j.elecom.2005.11.018

Sundeep D, Krishna AG, Ravikumar RVSSN, Kumar TV, Ephraim SD, Pavan YL (2016) Spectral characterization of mechanically synthesized MoO3-CuO nanocomposite. Int Nano Lett 6:119. doi:10.1007/s40089-015-0178-Z

Swift EJ Jr (1989) In vitro caries-inhibitory properties of a silver cermet. J Dent Res 68(6):1088-1093. doi:10.1177/ 00220345890680060601

Zhang JP, Chen P, Sun CH, Hu X (2006) Appl Catal A Gen 266:49-54. doi:10.1016/j.apcata.2004.01.025

Zhao G, Stevens SE (1998) Multiple parameters for the comprehensive evaluation of the susceptibility of Escherichia coli to the silver ion. Biometals 11(1):27-32. doi:10.1023/A: 1009253223055 